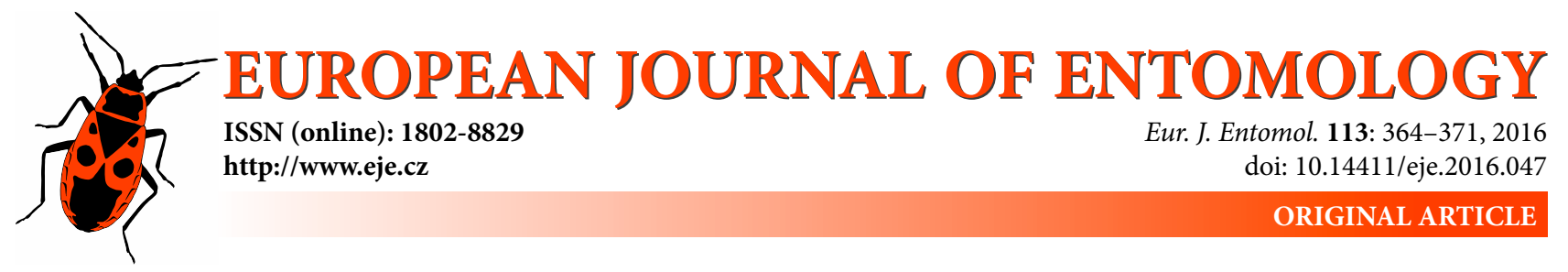

\title{
Diversity of adipokinetic hormones in termites (Isoptera)
}

\author{
VERONIKA JEDLIČKOVÁ1 ${ }^{\text {PAVEL JEDLIČKA }}{ }^{1}$ and BARBORA ŠPULÁKOVÁ ${ }^{2}$ \\ ${ }^{1}$ Faculty of Forestry and Wood Sciences, Czech University of Life Sciences Prague, Kamýcká 129, 16521 Prague 6 , \\ Czech Republic; e-mails: veronika.jedlickova@post.cz, jedlicka@uochb.cas.cz \\ ${ }^{2}$ Faculty of Agrobiology, Food and Natural Resources, Czech University of Life Sciences Prague, Kamýcká 129, \\ 16521 Prague 6, Czech Republic; e-mail: barboraspulakova@seznam.cz
}

Key words. Isoptera, termite, adipokinetic hormone, preprohormonal sequence, phylogenetic relationships

\begin{abstract}
In this study we report on the structural diversity of adipokinetic hormones (AKHs) in the evolutionarily oldest group of social insects, the termites (Isoptera). Using molecular methods combined with in silico bioinformatic analysis, we studied and compared the sequences coding for these neuropeptides in thirteen species of five families of Isoptera. There are three types of AKH octapeptides in termites: Empusa pennata adipokinetic hormone (Emppe-AKH; pQVNFTPNWamide), Microhodotermes viator corpus cardiacum peptide (Micvi-CC; pQINFTPNWamide) and Periplaneta americana cardioaccelerating hormone (PeramCAH-I; pQVNFSPNWamide). Of these the Peram-CAH-I was the most frequently bioactive form detected in representatives of four out of the six families studied. The complete AKH preprohormones in the termites studied shared at least an $84 \%$ amino acid similarity. In agreement with current phylogenetic scenarios of termites as an internal monophyletic clade nested within cockroaches (Blattaria) in the proximity of the family Blattidae, our phylogenetic analysis of the AKH precursor sequences (in the absence of data for the Cryptocercidae) placed the Blattidae (Periplaneta americana) as a sister group of termites and the AKHs of other cockroach families (Blattellidae and Blaberidae) were more divergent from those of termites. Representatives of the basal termite families Mastotermitidae and Archotermopsidae (but also one rhinotermitid genus Prorhinotermes) occurred separately from the phylogenetically advanced lineage (Rhinotermitidae and Termitidae), and Neotermes (Kalotermitidae) was sister to all other termites included.
\end{abstract}

\section{INTRODUCTION}

Adipokinetic hormones (AKHs) are well-known insect neuropeptides that have an important role in the control of metabolism. The AKHs are specified as mobilizing factors for a variety of energy reserves, such as carbohydrates, lipids and certain amino acids (Gäde et al., 1997; Gäde $\&$ Auerswald, 2003). AKHs are also involved in various physiological and biochemical processes such as stimulation of locomotion, enhancement of immune responses, activation of antioxidant mechanisms and inhibition of RNA synthesis (reviewed in Kodrík, 2008; Bednářová et al., 2013). AKHs are structurally similar to the red pigment concentrating hormone (RPCH) of crustaceans, which enables them to adopt the background colour (Fernlund \& Josefsson, 1972; Carlsen et al., 1976; Rao, 2001), and together belong to a widespread group of neuropeptides called the AKH/RPCH family.

AKHs are synthesized, stored and released predominantly from the paired endocrine retrocerebral glands, corpora cardiaca (CC), and there are small amounts of AKH reported in the brains of some insect species (Moshitzky et al., 1987; Kodrík et al., 2015). AKH is synthesized as a preprohormone consisting of a hydrophobic signal peptide, a bioactive neuropeptide and an AKH-associated peptide (Van der Horst et al., 2001). The signal peptide is removed co-translationally and the remaining prohormone is stored in the CC. The bioactive peptide is cleaved from the prohormone prior to its release into the hemolymph (O'Shea \& Rayne, 1992; Oudejans et al., 1999).

AKH bioactive peptides display several typical features such as a length of 8 to 10 amino acids, a blocked $\mathrm{N}$ terminus (pGlu) and C terminus (amide), aromatic residues at positions 4 (Phe or Tyr) and 8 (Trp), and Gly residue at position 9 (Gäde et al.,1997). Mass spectrometry has been used to identify the amino acid composition of bioactive peptides of dozens of species (Gäde, 2009; Gäde \& Marco, 2013). Structures of signal and AKH-associated peptides are detected mainly using classical molecular cloning and are available to a lesser extent. Sequences of both AKH bioactive peptides and the whole preprohomones are used to infer evolutionary relationships in insects (e.g. Liebrich et al., 1995; Kaufmann et al., 2009; Roth et al., 2009; Kodrík et al., 2010; Gäde et al., 2011).

Although the sequences of AKH neuropeptides are known for a wide range of insect taxa, there is a paucity of studies analyzing AKH preprohormonal sequences in a 
broad set of closely related species. Termites are a suitable taxon in this respect. They are a large and diversified group of hemimetabolous insects consisting of more than 3000 species (Krishna et al., 2013). Recent phylogenetic studies indicate that this group of eusocial insect is an ingroup of the cockroaches (Blattaria) and the subsocial wood-feeding genus Cryptocercus is its sister group (Lo et al., 2000; Klass \& Meier, 2006; Inward et al., 2007; Bourguignon et al., 2015). Two AKH bioactive octapeptides were previously found in termites: Micvi-CC in Microhodotermes viator, which seems to be unique for Isoptera, and PeramCAH-I in the termites Mastotermes darwiniensis and Trinervitermes trinervoides (Liebrich et al., 1995), which also occurs in various species of cockroaches and beetles (Coleoptera).

The aim of this study was to produce an overview of the AKH diversity in the phylogeny of Isoptera. We combined classical molecular biology approaches (5' and 3' RACE technique and cloning of cDNA) with bioinformatic analyses of massive parallel sequencing data to obtain $\mathrm{AKH}$ sequences for major lineages of both lower and higher termites. The predicted bioactive peptides and the complete preprohormonal sequences were subsequently used in comparative analyses within and between termites and their closest relatives, the cockroaches.

\section{MATERIALS AND METHODS}

\section{Experimental animals}

The termite species Hodotermopsis sjöstedti and Termes hospes were obtained from laboratory colonies of D. Sillam-Dussès, Institut de recherche pour le développement, Paris, France. Termites Coptotermes formosanus and Mastotermes darwiniensis were provided by R. Plarre, Federal Institute for Materials Research and Testing, Berlin, Germany. Species Coptotermes gestroi, Neotermes castaneus and Prorhinotermes simplex were provided by J. Šobotník, University of Life Sciences, Prague, Czech Republic. The other species were analyzed in silico and respective transcriptomic data were accessed from the public source of the NCBI Sequence Read Archive (see chapter Sequence analyses).

\section{Nucleic acid isolation}

Total RNA was extracted using TRI reagent (Sigma) following the manufacturer's protocol. RNA isolates were treated with TURBO DNase (Ambion) to remove traces of contaminating DNA.

\section{3' RACE PCR}

To obtain 3' end of AKH transcripts, we performed reverse transcription using the Superscript First-Strand Synthesis System for RT-PCR (Invitrogen) and $2 \mu \mathrm{g}$ of respective template RNA with an oligo-dT primer. The resulting cDNA was amplified in a subsequent PCR reaction using a $1 \mu \mathrm{l}$ aliquot of the RT reaction as a template, a reverse primer from the oligo-dT adapter and the degenerate forward primer AKH-3RACE (Table 1). Forward primer was designed based on the known amino acid composition of AKH bioactive peptide of Blatella germanica (FJ943774.1) and Periplaneta americana (AY622321.1). The PCR profile included initial denaturation $\left(2 \mathrm{~min}\right.$ at $\left.94^{\circ} \mathrm{C}\right), 35$ cycles of denaturation $\left(94^{\circ} \mathrm{C}\right.$ for $\left.1 \mathrm{~min}\right)$, primer annealing $(1 \mathrm{~min})$ and extension $\left(72^{\circ} \mathrm{C}\right.$ for $2 \mathrm{~min}$ ), followed by final extension at $72^{\circ} \mathrm{C}$ for $10 \mathrm{~min}$ The annealing temperature was $63^{\circ} \mathrm{C}$ in the first cycle and was decreased by $1^{\circ} \mathrm{C}$ in each subsequent cycle down to $55^{\circ} \mathrm{C}$, which was used for the rest of the reaction. The RT-PCR products were analyzed using agarose gel electrophoresis, cloned into pGEM-T Easy vector (Promega) and sequenced.

\section{5' RACE PCR}

The 5' ends of AKH transcripts were isolated using the FirstChoice RLM-RACE Kit (Invitrogen) with $10 \mu \mathrm{g}$ of the corresponding RNA according to manufacturer's instructions. Reverse transcriptions were carried out with gene specific primers derived from the previously sequenced 3' RACE PCR products (Table 1). PCR reactions were performed with $5^{\prime}$ RACE Outer Primer of RLM-RACE Kit and specific AKH reverse primers (Table 1). Subsequently, nested PCR was performed using an aliquot of purified product of the first round PCR, 5' RACE Inner Primer of RLM-RACE Kit and nested AKH reverse primer specific for each termite species (Table 1). All RT-PCR products were cloned into pGEM-T Easy vector (Promega) and sequenced.

\section{Sequence analyses}

The sequencing data for the transcriptomes of in silico analyzed termites were accessed from the public source of the NCBI Sequence Read Archive (SRA) using the SRA accession codes as follows: SRR863603.sra (Zootermopsis nevadensis), SRR789255.sra (Macrotermes natalensis), DRR013047. sra (Nasutitermes takasagoensis), SRR528715.sra (Odontotermes formosanus), SRR700381.sra (Reticulitermes flavipes), DRR013046.sra (Reticulitermes speratus). The raw data files were processed as described previously (Jedličková et al., 2015). Briefly, after conversion to a FASTQ file using fastq-dump utility in the SRA Toolkit (SRA Software page), the sequence read quality was monitored using FastQC and all reads trimmed using Trimmomatic software version 0.27 (Bolger et al., 2014). The previously cloned AKH cDNA sequence of Coptotermes formosanus (KT805304) was used as a reference and the resulting alignment process was completed using Bowtie2.1.0 (Langmead et al., 2009) and SAM/BAM processing (SAMtools; Li et al., 2009).

Table 1. List of primers used for cloning AKH transcripts.

\begin{tabular}{|c|c|}
\hline \multicolumn{2}{|l|}{ 3' RACE method } \\
\hline AKH-3RACE & 5' CARGTGAAYTTYTCNCCNGGCTGGGG 3' \\
\hline \multicolumn{2}{|l|}{$5^{\prime}$ RACE method } \\
\hline \multicolumn{2}{|c|}{ Reverse transcription } \\
\hline C. formosanus & 5' GTACAAGTCAGGTAATTATCATAGAGG 3' \\
\hline C. gestroi & 5' TCTGTCGTTTTAGACTAAGCAGG 3' \\
\hline H. sjöstedti & 5' TTGCTCCGAATTTCTCACAGTC 3' \\
\hline M. darwiniensis & 5' CTGACAACGGGAGTTAATTTGCTC 3' \\
\hline N. castaneus & 5' TCTTGTTCTGGAGTAAGCAGGAG 3' \\
\hline P. simplex & 5' AGATCGGGTAATCATCATAGATGG 3' \\
\hline T. hospes & 5' TATTCGTCTTTTGGAATTAAGCAGGG 3' \\
\hline \multicolumn{2}{|l|}{ PCR } \\
\hline C. formosanus & 5' TCTGTCGTTTTAGACTAAGCAGGGAAAC 3' \\
\hline C. gestroi & 5' CCGAATTTCTCACAGTCCACCAGT 3' \\
\hline H. sjöstedti & 5' TCCACCAGTTTCTGTGCTTCACTC 3' \\
\hline M. darwiniensis & 5' TTCTCACAGTCCACCAGTTTCTGGG 3' \\
\hline N. castaneus & 5' TGCTCCAAATTTCTCACATTCCACCAG 3' \\
\hline P. simplex & 5' CGTGAATTAGTTTGCACCGAATTTGTC 3' \\
\hline T. hospes & 5' CCGAATTTCTCACAGTCCACCAGTTTC 3' \\
\hline \multicolumn{2}{|l|}{ Nested PCR } \\
\hline C. formosanus & 5' GAATTTCTCACAGTCCACCAGTTTCTGG 3' \\
\hline C. gestroi & 5' CCAGTTTCTGGGCTTCATTCTGAATGA 3' \\
\hline H. sjöstedti & 5' GAGCTTCTGTAGAAGTCTTGCATGGAC 3' \\
\hline M. darwiniensis & 5' CTGGGCTTCACTCTGAATCAGTTTGTAG 3' \\
\hline N. castaneus & 5' CAGTTTCTGGGCTTCGTTCTGGATG 3' \\
\hline P. simplex & 5' TTTGTCGCAGTCCACCAGTTTCTGC 3' \\
\hline T. hospes & 5' ATCAAGGGCTCTGTAGACGCCTTGC 3' \\
\hline
\end{tabular}


The resulting cDNA sequences were translated into proteins in silico and the respective ORFs (i.e. the preprohormonal AKH sequences) determined.

Multiple sequence comparison was performed using CLUSTALW (Thompson et al., 1994) and consequent phylogenetic analysis using the neighbour-joining and maximumlikelihood methods in the SeaView program (Gouy et al., 2010). Bootstrap values were calculated based on 1000 replications in both analyses. The resulting phylogenetic trees were edited using FigTree software (version 1.4.2.; http://tree.bio.ed.ac.uk/software/figtree/).

Pairwise protein sequence alignment of AKH precursors was done using the EMBOSS Stretcher tool (http://www.ebi.ac.uk/ Tools/psa/emboss_stretcher/). The GenBank accession numbers of the species studied used in the preprohormonal similarity comparisons are as follows: Blattaria, B. discoidalis (Q17128.1), B. germanica (ADB91364.1), P. americana (AAV41425.1); Diptera, Aedes aegypti (XP 001655817.1), Anopheles gambiae (XP_001689190.1), Culex pipiens (FN391985.1), Bactrocera dorsalis (XP 011211021.1), Ceratitis capitata (XP 004526727.1), Drosophila melanogaster (NP 523918.1), Musca domestica (XP_005178897.1); Hemiptera, Aphis gossypii (KT456556.1), Acyrthosiphon pisum (JQ086350.1), Diaphorina citri (XP 008488257.1), Dreyfusia spp. (KP300868.1), Nilaparvata lugens (BAO00932.1), Pseudoregma bambucicola (KP300867.1), Pyrrhocoris apterus (Pyrap-AKH, AGZ62588.1; Peram-CAH-II, AGZ62589.1), Rhodnius prolixus (KM283242.1), Sitobion avenae (KT456557.1).

\section{RESULTS AND DISCUSSION}

Termites are a species-rich group of social insects that was traditionally classified at the taxonomic rank of order (Isoptera). However, in the past decade, evidence of a sister-group relationship between termites and the wood roaches of the genus Cryptocercus have accumulated (Lo et al., 2000; Inward et al., 2007; Legendre et al., 2008; Cameron et al., 2012; Djernaes et al., 2012). Thus, termites are now considered as "highly advanced social roaches" and classified as a subgroup Isoptera within the order Blattaria (e.g., as an infraorder in Krishna et al., 2013). Within termites, there are currently nine families containing extant species: Mastotermitidae, Hodotermitidae, Archotermopsidae, Stolotermitidae, Kalotermitidae, Stylotermitidae, Rhinotermitidae, Serritermitidae and Termitidae (Engel et al., 2009). Nevertheless, recent phylogenetic studies based on morphological and/or molecular characters yield tree topologies slightly different from one another (reviewed in Krishna et al., 2013) and the phylogenetic relationships within termites are currently widely debated (Bourguignon et al., 2015; Legendre et al., 2015).

Liebrich et al. (1995) used mass spectrometry to identify AKH bioactive peptides in representatives of three termite families, Mastotermes darwiniensis (Mastotermitidae), Microhodotermes viator (Hodotermitidae) and Trinervitermes trinervoides (Termitidae). A novel type of neurohormone was detected in $M$. viator (Micvi-CC; pQINFTPNWamide), whereas in M. darwiniensis and T. trinervoides the sequence of Peram-CAH-I (pQVNFSPNWamide) was recorded. This bioactive peptide is also recorded in representatives of the family Blattidae, in two families of Coleoptera and in the hemipteran Locris arithmetica (re-

C. formosanus
C. gestroi
M. darwiniensis
M. natalensis
N. castaneus
N. takasagoensis
O. formosanus
P. simplex
R. flavipes
R. speratus
T. hospes

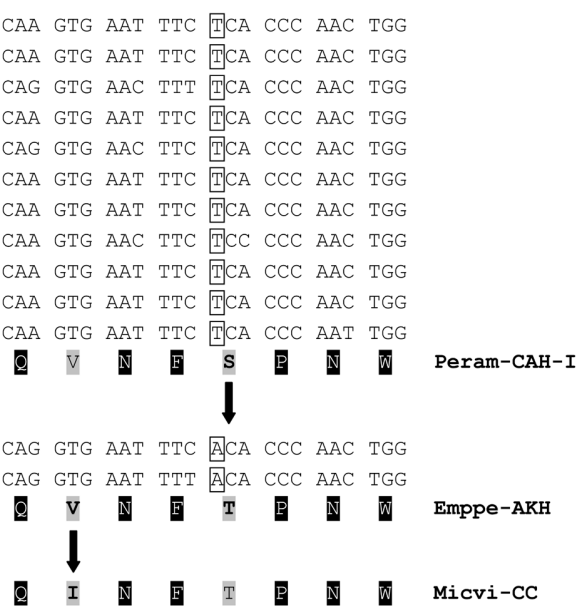

M. viator

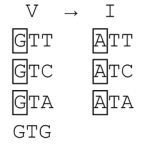

Fig. 1. Proposed model for the formation of the different adipokinetic peptides detected in termites. Arrows indicate the changes in amino acids; conserved residues are boxed with the color black, and similar with grey background. Differences in nucleotides are highlighted in boxes. For Micvi-CC, for which no DNA data are available, a hypothetic scenario for a point mutation leading to the substitution of amino acids (valine to isoleucine) is given.

viewed in Gäde, 2009). We detected a sequence of the Peram-CAH-I peptide in other termite families, namely in Kalotermitidae and Rhinotermitidae (Table 2). The Emppe-AKH (pQVNFTPNWamide), previously reported in Mantodea (Gäde, 1991), also occurs in the termite family Archotermopsidae (Table 2). All peptides only differ at positions 2 (isoleucine/valine) and 5 (serine/threonine).

In termites, we detected a single form of AKH in each of the species studied and all predicted bioactive peptides consisted of 8 amino acids. In this respect, there is a greater variety in the cockroaches, the closest relatives of termites. In two families, Blaberidae and Blattellidae, a single AKH (Bladi-HrTH) consisting of 10 amino acids was found, while in families Blattidae and Polyphagidae, two AKH octapeptides were recorded in one species, i.e. Peram-CAH-I and -II in Blattidae, and Polae-HrTH and Tenmo-HrTH in Polyphaga aegyptiaca (Polyphagidae; reviewed in Gäde, 2009; see Table 2). The occurrence of two bioactive peptides in one species might indicate a different role for each AKH in the metabolism as in Locusta migratoria and Pyrrhocoris apterus (Bártů et al., 2010; Tomčala et al., 2010).

The most frequent form of $\mathrm{AKH}$ recorded in termites is Peram-CAH-I (Table 2). It is thought to be the ancestral type of AKH peptide in Chrysomelidae, in which there are two other types of AKH peptides (Emppe-AKH and Peram-CAH-II). The phylogenetic scenario of Gäde \& Marco (2011) proposes a replacement of nucleotide $\mathrm{T}$ in position one of the genetic code for serine in Peram-CAH-I by A to code for threonine in Emppe-AKH; subsequent nucleotide changes then lead to the formation of Peram-CAH-II peptide. Peram-CAH-I also appears to be the ancestral peptide 
Table 2. AKH peptides of Blattaria and Isoptera. In Blattaria, one representative is shown for each genus for which several species have been studied. * - in E. capucina and T. petiveriana a single AKH (Tenmo-HrTH) was studied.

\begin{tabular}{|c|c|c|c|c|c|}
\hline \multicolumn{2}{|c|}{ Taxonomic affiliation } & $\begin{array}{l}\text { Species name } \\
\text { Aptera fusca }\end{array}$ & $\begin{array}{l}\text { References } \\
\text { Roth et al., } 2009\end{array}$ & $\begin{array}{l}\text { Neuropeptide } \\
\text { name }\end{array}$ & $\begin{array}{l}\text { Amino acid } \\
\text { sequence }\end{array}$ \\
\hline \multirow[t]{5}{*}{ Blattaria } & Blaberidae & $\begin{array}{l}\text { Aptera fusca } \\
\text { Archimandrita tessellata } \\
\text { Bantua robusta } \\
\text { Blaberus discoidalis } \\
\text { Blaptica dubia } \\
\text { Blepharodera discoidalis } \\
\text { Diploptera punctata } \\
\text { Elliptorhina sp. } \\
\text { Eublaberus distanti } \\
\text { Gromphadorhina portentosa } \\
\text { Gyna caffrorum } \\
\text { Leucophaea maderae } \\
\text { Lucihormetica grossei } \\
\text { Nauphoeta cinerea } \\
\text { Panaesthia sp. } \\
\text { Panchlora viridis } \\
\text { Princisia vanwaerebeki }\end{array}$ & $\begin{array}{l}\text { Roth et al., } 2009 \\
\text { Roth et al., } 2009 \\
\text { Roth et al., } 2009 \\
\text { Hayes et al., } 1986 \\
\text { Roth et al., } 2009 \\
\text { Roth et al., } 2009 \\
\text { Roth et al., } 2009 \\
\text { Roth et al., } 2009 \\
\text { Roth et al., } 2009 \\
\text { Gäde \& Rinehart, } 1990 \\
\text { Roth et al., } 2009 \\
\text { Gäde \& Rinehart, } 1990 \\
\text { Roth et al., 2009 } \\
\text { Gäde \& Rinehart, } 1986 \\
\text { Roth et al., } 2009 \\
\text { Roth et al., } 2009 \\
\text { Roth et al., } 2009\end{array}$ & \multirow[t]{2}{*}{ Bladi-HrTH } & \multirow[t]{2}{*}{$\begin{array}{l}\text { pQVNFSPGWGT- } \\
\text { amide }\end{array}$} \\
\hline & Blattellidae & $\begin{array}{l}\text { Blattella germanica } \\
\text { Loboptera decipiens }\end{array}$ & $\begin{array}{l}\text { Gäde \& Rinehart, 1990; Veenstra \& Camps, } 1990 \\
\text { Roth et al., } 2009\end{array}$ & & \\
\hline & Blattidae & $\begin{array}{l}\text { Blatta orientalis } \\
\text { Brinckia hanstroemi } \\
\text { Celatoblatta sp. } \\
\text { Deropeltis erythrocephala } \\
\text { Eurycotis floridana } \\
\text { Neostylopyga rhombifolia } \\
\text { Periplaneta americana } \\
\text { Pseudoderopeltis foveolata } \\
\text { Shelfordella lateralis }\end{array}$ & $\begin{array}{l}\text { Gäde \& Rinehart, } 1990 \\
\text { Predel \& Gäde, } 2005 \\
\text { Predel \& Gäde, } 2005 \\
\text { Predel \& Gäde, } 2005 \\
\text { Predel \& Gäde, } 2005 \\
\text { Predel \& Gäde, } 2005 \\
\text { Scarborough et al., 1984; Witten et al., } 1984 \\
\text { Predel \& Gäde, } 2005 \\
\text { Predel \& Gäde, } 2005\end{array}$ & $\begin{array}{l}\text { Peram-CAH-I } \\
+ \\
\text { Peram-CAH-II }\end{array}$ & $\begin{array}{l}\text { pQVNFSPNWamide } \\
+ \\
\text { pQLTFTPNWamide }\end{array}$ \\
\hline & Polyphagidae & $\begin{array}{l}\text { Ergaula capucina* } \\
\text { Polyphaga aegyptiaca } \\
\text { Therea petiveriana* }\end{array}$ & $\begin{array}{l}\text { Konig \& Gäde, } 2005 \\
\text { Gäde \& Kellner, } 1992 \\
\text { Roth et al., } 2009\end{array}$ & $\begin{array}{l}\text { Tenmo-HrTH } \\
+ \\
\text { Polae-HrTH }\end{array}$ & $\begin{array}{l}\text { pQLNFSPNWamide } \\
+ \\
\text { pQITFTPNWamide }\end{array}$ \\
\hline & Cryptocercidae & Cryptocercus darwini & Roth et al., 2009 & Tenmo-HrTH & pQLNFSPNWamide \\
\hline \multirow{5}{*}{ Isoptera } & $\frac{\text { Mastotermitidae }}{\text { Kalotermitidae }}$ & $\begin{array}{l}\text { Mastotermes darwiniensis } \\
\text { Neotermes castaneus }\end{array}$ & $\begin{array}{l}\text { Liebrich et al., 1995; This study } \\
\text { This study }\end{array}$ & Peram-CAH-I & pQVNFSPNWamide \\
\hline & Termopsidae & $\begin{array}{l}\text { Hodotermopsis sjöstedti } \\
\text { Zootermopsis nevadensis }\end{array}$ & $\begin{array}{l}\text { This study } \\
\text { This study }\end{array}$ & Emppe-AKH & pQVNFTPNWamide \\
\hline & Hodotermitidae & Microhodotermes viator & Liebrich et al., 1995 & Micvi-CC & pQINFTPNWamide \\
\hline & Rhinotermitidae & $\begin{array}{l}\text { Coptotermes formosanus } \\
\text { Coptotermes gestroi } \\
\text { Prorhinotermes simplex } \\
\text { Reticulitermes flavipes } \\
\text { Reticulitermes speratus }\end{array}$ & $\begin{array}{l}\text { This study } \\
\text { This study } \\
\text { This study } \\
\text { This study } \\
\text { This study }\end{array}$ & \multirow{2}{*}{ Peram-CAH-I } & \multirow{2}{*}{ pQVNFSPNWamide } \\
\hline & Termitidae & $\begin{array}{l}\text { Odontotermes formosanus } \\
\text { Macrotermes natalensis } \\
\text { Nasutitermes takasagoensis } \\
\text { Trinervitermes trinervoides } \\
\text { Termes hospes }\end{array}$ & $\begin{array}{l}\text { This study } \\
\text { This study } \\
\text { This study } \\
\text { Liebrich et al., } 1995 \\
\text { This study }\end{array}$ & & \\
\hline
\end{tabular}

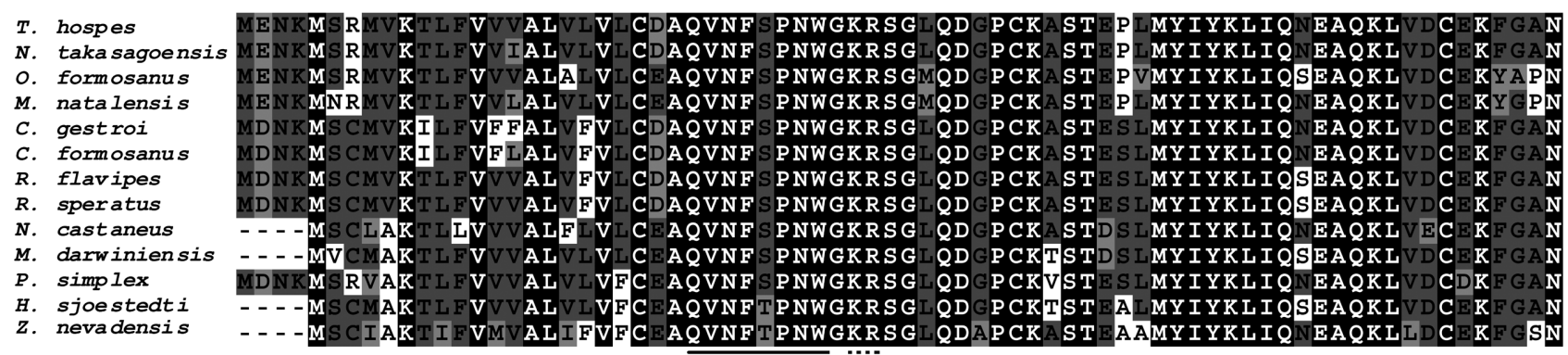

Fig. 2. Alignment of AKH preprohormones in termites. Conserved residues are boxed with the color black, identical with dark grey, and similar with light grey background. In the preprohormonal sequence, the initial part represents a signal peptide that precedes the AKH bioactive peptide (underlined with a solid line). The processing site is underlined with a dotted line followed by the AKH-associated peptide. 
A

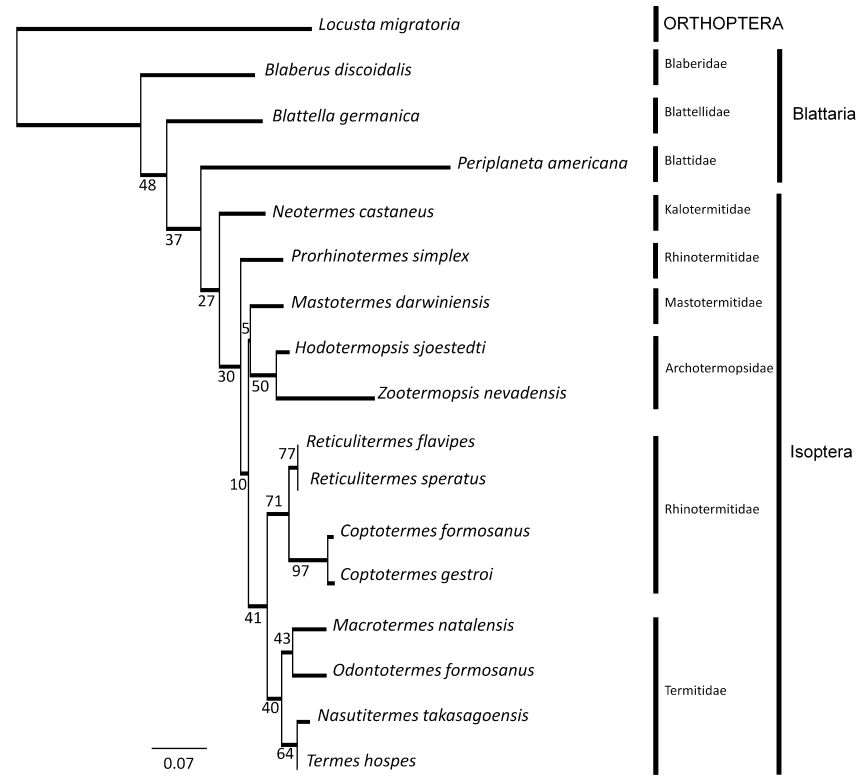

$\mathrm{B}$

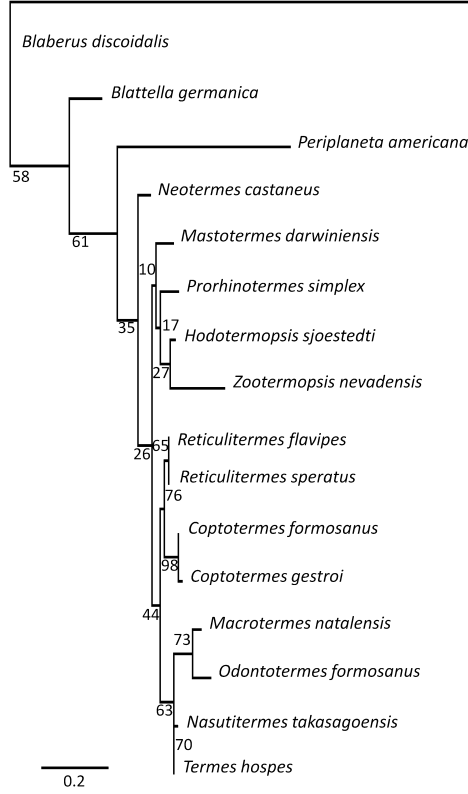

\begin{tabular}{l|l} 
Locusta migratoria & ORTHOPTERA
\end{tabular}

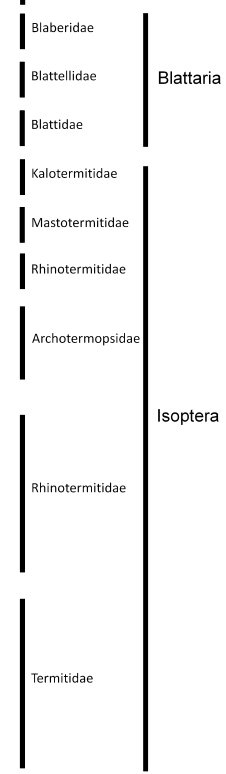

C

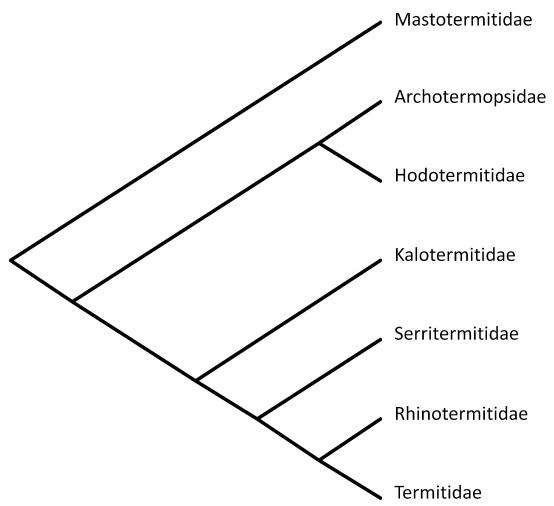

Fig. 3. Phylogenetic analysis of preprohormonal AKH sequences of termites (Isoptera) and cockroaches (Blattaria). The neighbour-joining (A) and maximum-likelihood (B) methods were used and the resulting trees were rooted using the precursor of AKH-1 of Locusta migratoria (Orthoptera; CAA60494.1). Bootstrap values were calculated based on 1000 replications in both analyses and cited for each branch. (C) A view of the phylogeny of termites adopted from Thompson et al. (2000) and Legendre et al. (2008). 
in termites; a point mutation leading to the substitution of serine in Peram-CAH-I to threonine in Emppe-AKH is obvious from the DNA data shown in Fig. 1. A subsequent single nucleotide substitution may have lead to the formation of Micvi-CC, a third type of AKH detected in termites (Fig. 1). Interestingly, Peram-CAH-I is not shared with the phylogenetically closest family of cockroaches, Cryptocercidae (Table 2). Nevertheless, Tenmo-HrTH (pQLNFSPNWamide) detected in $C$. darwini differs only in the occurrence of leucine at position 2 in comparison to valine in Peram-CAH-I (pQVNFSPNWamide); a single nucleotide substitution $(\mathrm{C} / \mathrm{G}$ in position one of the genetic code) may have lead to the replacement of this amino acid.

The sequences of AKH bioactive peptides were used to investigate phylogenetic relationships in Dictyoptera and the results are in agreement with contemporary views of the phylogeny of this taxon (Liebrich et al., 1995; Roth et al., 2009). To test whether the sequence of a large AKH precursor protein will be similarly suitable for the reconstruction of phylogenetic relationships we compared preprohormonal sequences of representatives of all major phylogenetic lineages of termites. The sequences obtained by both cloning and bioinformatic analysis are available from GenBank (accession numbers KT805304-KT805316).

The alignment of AKH preprohormones of the termite species examined is shown in Fig. 2. The amino acid (aa) similarity, recorded in representatives of five families of termites, was at least $84 \%$. Congeneric species showed either identical aa sequences ( $R$. flavipes and $R$. speratus) or only one aa substitution (C. formosanus and $C$. gestroi). The latter case was recorded also in species of different genera, namely in T. hospes and $N$. takasagoensis (Termitidae). Preprohormones of termites compared to those of Periplaneta americana (Blattidae, for which there is only a whole preprohormonal sequence available for PeramCAH-II), Blaberus discoidalis (Blaberidae, Bladi-HrTH) and Blatella germanica (Blattellidae, Bladi-HrTH), share from $74 \%$ to $89 \%$ aa similarity. In general, the within-order similarity of AKH precursor sequences greatly varies among individual orders. For example, AKHs in representatives of different families in Diptera and Hemiptera share generally $50 \%-70 \%$ of aa similarity. The aphids represent the exception in Hemiptera with an $81 \%$ aa similarity detected between representatives of Aphididae (Acyrthosiphon pisum and Sitobion avenae) and a member of Adelgidae (Dreyfusia spp.). Among dipteran species, the highest value $(78 \%)$ was detected between AKHs of Musca domestica (Muscidae) and Drosophila melanogaster (Drosophilidae; see Material and methods for species studied and their GenBank accession numbers). Thus, the high level of similarity found in termite AKH precursors resemble more the values detected within the rank of family than whole orders in other insect groups. Nevertheless, more data of the whole preprohormones in different taxa would be necessary to depict any trends in AKH sequences.

The phylogenetic analysis of all of the AKH preprohormones was carried out in order to reveal relationships within termites and also between termites and cockroaches.
Since we did not obtain data of representatives of all termite families, the simplified view of phylogenetic relationships within termites presented by Thompson et al. (2000) and Legendre et al. (2008) was accepted as a plausible hypothesis for comparison (Fig. 3). Using two different methods of reconstructing trees (neighbour-joining and maximum-likelihood analyses) the termites (in the absence of data for the Cryptocercidae) clustered as a sister group of Blattidae (represented by P. americana), whereas members of the other cockroach families (Blattellidae and Blaberidae) were assigned to more distant clades. This pattern is in accordance with the recent classification of Blattaria (Legendre et al., 2008; Djernaes et al., 2012). The clustering within termites based on the AKH precursors revealed some divergences from the views of termite phylogeny based on morphological traits (Engel et al., 2009) and/ or nucleotide sequences (Fig. 3C; Legendre et al., 2008). Mainly, the AKH of $N$. castaneus (Kalotermitidae) differed the most from that of the preprohormones of other species (Fig. 3A, B) and also from its expected phylogenetic position (compare with Fig. 3C). In addition, P. simplex (Rhinotermitidae) was segregated from other termite species in the phylogenetic tree reconstructed using the neighbourjoining method (Fig. 3A), whereas this species was placed in the Mastotermitidae/Archotermopsidae cluster in the maximum-likelihood tree (Fig. 3B). The remaining AKH sequences were placed in two separate clusters by both methods. The first cluster also included the phylogenetically primitive termites, $M$. darwiniensis (Mastotermitidae), and $H$. sjoestedti and $Z$. nevadensis (Archotermopsidae), whereas the second cluster encompassed the monophylum Neoisoptera, which included the families Rhinotermitidae (except Prorhinotermes) and Termitidae (Fig. 3). This cluster had the highest bootstrap value and the phylogenetic position of the termites was as in the recent classification (Krishna et al., 2013). In short, with a few exceptions, the phylogenetic analysis based on AKH precursors is similar to the common termite phylogeny at the family level.

\section{CONCLUSIONS}

We analyzed and compared the AKH bioactive peptides and preprohormonal sequences of 13 species from all major phylogenetic lineages of termites. Three types of AKH bioactive peptides were detected in Isoptera, with Peram-CAH-I the most frequent form. Phylogenetic analysis of $\mathrm{AKH}$ preprohormonal sequences revealed that most of the species studied were clustered according to their expected affiliation at the family level. The exceptions are the sequences of $N$. castaneus and $P$. simplex, which diverge most from the AKH precursors of other species.

ACKNOWLEDGEMENTS. This study was financially supported by the University Internal Grant Agency of the Czech University of Life Sciences Prague, Czech Republic (CIGA, project no. 20144306). The authors thank R. Plarre (Federal Institute for Materials Research and Testing, Berlin, Germany) and D. Sillam-Dussès (Institut de recherche pour le développement, Paris, France) for providing termite samples. 


\section{REFERENCES}

BÁrtư I., TomČala A., Socha R., ŠImeK P. \& Kodrík D. 2010: Analysis of lipids mobilized by adipokinetic hormones in the firebug Pyrrhocoris apterus (Heteroptera: Pyrrhocoridae). Eur. J. Entomol. 107: 509-520.

BednáR̆ovÁ A., KodríK D. \& KRISHnAN N. 2013: Unique roles of glucagon and glucagon-like peptides: Parallels in understanding the functions of adipokinetic hormones in stress responses in insects. - Comp. Biochem. Physiol. (A) 164: 91-100.

Bolger A.M., Lohse M. \& Usadel B. 2014: Trimmomatic: A flexible trimmer for Illumina Sequence Data. - Bioinformatics 30: 2114-2120.

Bourguignon T., Lo N., Cameron S.L., Šobotník J., Hayashi Y., Shigenobu S., Watanabe D., Roisin Y., Miura T. \& Evans T.A. 2015: The evolutionary history of termites as inferred from 66 mitochondrial genomes. - Mol. Biol. Evol. 32: 406-421.

Cameron S.L., Lo N., Bourguignon T., Svenson G.J. \& Evans T.A. 2012: A mitochondrial genome phylogeny of termites (Blattodea: Termitoidae): robust support for interfamilial relationships and molecular synapomorphies define major clades. - Mol. Phylogenet. Evol. 65: 163-173.

Carlsen J., Christensen M. \& Josefsson L. 1976: Purification and chemical structure of the red pigment-concentrating hormone of the prawn Leander adspersus. - Gen. Comp. Endocrinol. 30: 327-331.

Djernaes M., Klass K.D., Picker M.D. \& Damgaard J. 2012: Phylogeny of cockroaches (Insecta, Dictyoptera, Blattodea), with placement of aberrant taxa and exploration of out-group sampling. - Syst. Entomol. 37: 65-83.

Engel M.S, Grimaldi D.A. \& Krishna K. 2009: Termites (Isoptera): Their phylogeny, classification, and rise to ecological dominance. - Am. Mus. Novit. 3650: 1-27.

FERnLUND P. \& JosefsSon L. 1972: Crustacean color-change hormone: amino acid sequence and chemical synthesis. - Science 177: $173-175$.

GÄDE G. 1991: The adipokinetic neuropeptide of Mantodea: sequence elucidation and evolutionary relationships. - Biol. Chem. Hoppe-Seyler 372: 193-201.

GäDE G. 2009: Peptides of the adipokinetic hormone/red pigment-concentrating hormone family: a new take on biodiversity. - Ann. N. Y. Acad. Sci. 1163: 125-136.

GÄDE G. \& AUERSWALD L. 2003: Mode of action of neuropeptides from the adipokinetic hormone family. - Gen. Comp. Endocrinol. 132: 10-20.

GÄDE G. \& MARCO H.G. 2011: The adipokinetic hormone family in Chrysomeloidea: structural and functional considerations. - Zookeys 157: 81-94.

GädE G. \& MARCo H.G. 2013: AKH/RPCH peptides. In Kastin A.J. (eds): Handbook of Biologically Active Peptides. Academic Press, San Diego, pp. 185-190.

Gäde G., Hoffmann K.H. \& Spring J.H. 1997: Hormonal regulation in insects: facts, gaps, and future directions. - Physiol. Rev. 77: 963-1032.

Gäde G., Simek P. \& Fescemyer H.W. 2011: Adipokinetic hormones provide inference for the phylogeny of odonata. $-J$. Insect Physiol. 57: 174-178.

Gouy M., Guindon S. \& Gascuel O. 2010: SeaView version 4: a multiplatform graphical user interface for sequence alignment and phylogenetic tree building. - Mol. Biol. Evol. 27: 221-224.

InWARD D., BeCCAloni G. \& EGgLETon P. 2007: Death of an order: a comprehensive molecular phylogenetic study confirms that termites are eusocial cockroaches. - Biol. Lett. 3: 331-335.
JedLIČKovÁ V., JedLIČKa P. \& LeE H.J. 2015: Characterization and expression analysis of adipokinetic hormone and its receptor in eusocial aphid Pseudoregma bambucicola. - Gen. Comp. Endocrinol. 223: 38-46.

Kaufmann C., Merzendorfer H. \& Gäde G. 2009: The adipokinetic hormone system in Culicinae (Diptera: Culicidae): molecular identification and characterization of two adipokinetic hormone (AKH) precursors from Aedes aegypti and Culex pipiens and two putative AKH receptor variants from $A$. aegypti. —Insect Biochem. Mol. Biol. 39: 770-781.

Klass K.D. \& Meier R. 2006: A phylogenetic analysis of Dictyoptera (Insecta) based on morphological characters. - Entomol. Abh. 63: 3-50.

KoDRík D. 2008: Adipokinetic hormone functions that are not associated with insect flight. - Physiol. Entomol. 33: 171-180.

Kodrík D., Marco H.G., Šimek P., Socha R., Štys P. \& Gäde G. 2010: The adipokinetic hormones of Heteroptera: a comparative study. - Physiol. Entomol. 35: 117-127.

Kodrík D., StašKová T., JedličKová V., Weyda F., ZÁvodská R. \& Pflegerová J. 2015: Molecular characterization, tissue distribution, and ultrastructural localization of adipokinetic hormones in the CNS of the firebug Pyrrhocoris apterus (Heteroptera, Insecta). — Gen. Comp. Endocrinol. 210: 1-11.

Krishna K., Grimaldi D.A., Krishna V. \& Engel M.S. 2013: Treatise on the Isoptera of the world. - Bull. Am. Mus. Nat. Hist. 377: 1-2704.

Langmead B., Trapnell C., Pop M. \& Salzberg S.L. 2009: Ultrafast and memory-efficient alignment of short DNA sequences to the human genome. - Genome Biol. 10: R25, $10 \mathrm{pp}$.

Legendre F., Whiting M.F., Bordereau C., Cancello E.M., Evans T.A. \& GRANDCOLAS P. 2008: The phylogeny of termites (Dictyoptera: Isoptera) based on mitochondrial and nuclear markers: Implications for the evolution of the worker and pseudergate castes, and foraging behaviors. - Mol. Phylogenet. Evol. 48: 615-627.

Legendre F., Nel A., Svenson G.J., Robillard T., Pellens R. \& GrandColas P. 2015: Phylogeny of Dictyoptera: Dating the origin of cockroaches, praying mantises and termites with molecular data and controlled fossil evidence. - PLOS ONE 10: e0130127, 27 pp.

Li H., Handsaker B., Wysoker A., Fennell T., Ruan J., Homer N., Marth G., Abecasis G. \& Durbin R. 2009: The Sequence Alignment/Map format and SAMtools. - Bioinformatics 25: 2078-2079.

LIEBRICH W., KellnER R. \& GÄDE G. 1995: Isolation and primary structures of neuropeptides of the AKH/RPCH family from various termite species. - Peptides 16: 559-564.

Lo N., Tokuda G., Watanabe H., Rose H., Slaytor M., Maekawa K., BANDI C. \& NodA H. 2000: Evidence from multiple gene sequences indicates that termites evolved from wood-feeding cockroaches. - Curr. Biol. 10: 801-804.

Moshitzky P., Henzel W.J., Rafaeli A., Ramachandran J. \& ApPLEBAUM S.W. 1987: Synthesis of adipokinetic hormone (AKHI) in the locust brain. - Insect Biochem. 17: 1133-1137.

O'Shea M. \& Rayne R.C. 1992: Adipokinetic hormones: cell and molecular biology. - Experientia 48: 430-438.

Oudejans R.C., Harthoorn L.F., Diederen J.H. \& VAN DER Horst D.J. 1999: Adipokinetic hormones. Coupling between biosynthesis and release. - Ann. N. Y. Acad. Sci. 897: 291-299.

RAO K.R. 2001: Crustacean pigmentary-effector hormones: chemistry and functions of RPCH, PDH, and related peptides. - Am. Zool. 41: 364-379.

Roth S., Fromm B., Gäde G. \& Predel R. 2009: A proteomic approach for studying insect phylogeny: CAPA peptides of 
ancient insect taxa (Dictyoptera, Blattoptera) as a test case. BMC Evol. Biol. 9: 50.

Thompson G.J., Kitade O., Lo N. \& Crozier R.H. 2000: Phylogenetic evidence for a single, ancestral origin of a 'true' worker caste in termites. - J. Evol. Biol. 13: 869-881.

Thompson J.D., Higgins D.G. \& Gibson T.J. 1994: CLUSTAL $\mathrm{W}$ : improving the sensitivity of progressive multiple sequence alignment through sequence weighting, position-specific gap penalties and weight matrix choice. - Nucl. Acids Res. 22: $4673-4680$.
TomČAla A., BÁrtŮ I., ŠIMEK P. \& KodRíK D. 2010: Locust adipokinetic hormones mobilize diacylglycerols selectively. Comp. Biochem. Phys. (B) 156: 26-32.

VAn der Horst D.J., Van MarrewiJK W.J.A. \& Diederen J.H.B. 2001: Adipokinetic hormones of insect: release, signal transduction, and responses. - Int. Rev. Cytol. 211: 179-240.

Received December 1, 2015; revised and accepted March 4, 2016 Published online April 26, 2016 